\title{
Radiofrequency Energy Loop Primes Cardiac, Neuronal, and Skeletal Muscle Differentiation in Mouse Embryonic Stem Cells: A New Tool for Improving Tissue Regeneration
}

\author{
Margherita Maioli, $* \dagger$ Salvatore Rinaldi, $\neq \S$ Sara Santaniello, $* \dagger$ Alessandro Castagna, $\neq$ \\ Gianfranco Pigliaru, $*+$ Sara Gualini, $* \dagger$ Vania Fontani, $\neq$ and Carlo Ventura $† \llbracket \#$
}

\author{
*Department of Biomedical Sciences, University of Sassari, Sassari, Italy \\ $\nmid$ Laboratory of Molecular Biology and Stem Cell Engineering, National Institute of Biostructures and Biosystems, Bologna, Italy \\ \$Rinaldi Fontani Institute, Florence, Italy \\ $\S$ Medical School of Occupational Medicine, University of Florence, Florence, Italy \\ ICCardiovascular Department, S. Orsola-Malpighi Hospital, University of Bologna, Bologna, Italy \\ \#Bioscience Institute, Falciano, Republic of San Marino
}

\begin{abstract}
Radiofrequency (RF) waves from Wi-Fi (wireless fidelity) technologies have become ubiquitous, with Internet access spreading into homes, and public areas. The human body harbors multipotent stem cells with various grading of potentiality. Whether stem cells may be affected by Wi-Fi RF energy remains unknown. We exposed mouse embryonic stem (ES) cells to a Radio Electric Asymmetric Conveyer (REAC), an innovative device delivering Wi-Fi RF of $2.4 \mathrm{GHz}$ with its conveyer electrodes immersed into the culture medium. Cell responses were investigated by real-time PCR, Western blot, and confocal microscopy. Single RF burst duration, radiated power, electric and magnetic fields, specific absorption rate, and current density in culture medium were monitored. REAC stimulation primed transcription of genes involved in cardiac (GATA4, Nkx-2.5, and prodynorphin), skeletal muscle (myoD) and neuronal (neurogenin1) commitment, while downregulating the self renewal/pluripotency-associated genes Sox2, Oct4, and Nanog. REAC exposure enhanced the expression of cardiac, skeletal, and neuronal lineage-restricted marker proteins. The number of spontaneously beating ES-derived myocardial cells was also increased. In conclusion, REAC stimulation provided a "physical milieu" optimizing stem cell expression of pluripotentiality and the attainment of three major target lineages for regenerative medicine, without using chemical agonists or vectormediated gene delivery.
\end{abstract}

Key words: Radiofrequency waves; Wifeless fidelity (Wi-Fi); Stem cells; Tissue regeneration

\section{INTRODUCTION}

Radiofrequency (RF) waves have long been used for different types of information exchange via the airwaves, wireless Morse code, radio, television, and wireless telephony. In addition to the increasing prevalence of cellular telephones, there has been continuing expansion of wireless Internet access, such as Wi-Fi (wireless fidelity), into homes, schools, workplaces, and public areas, supporting local, over-the-air computer communication via a wireless local area network (WLAN). Typically, the transmission frequency is approximately 2.4 or $5.5 \mathrm{GHz}$, and $\mathrm{Wi}-\mathrm{Fi}$ provides data transmission rates in the range of 1-50 Mbps (megabytes per second). There is increasing evidence that cellular homeostasis, not only is affected by chemical agonists, but can also be regulated by physical stimuli. We have previously shown that exposure of mouse embryonic stem (ES) cells to extremely low frequency $(50 \mathrm{~Hz}, 0.8 \mathrm{~m} \mathrm{Trms})$ magnetic fields remarkably increased the transcription of cardiogenic and cardiac-specific genes, enhancing the yield of ES-derived cardiomyocytes (32). The human body harbors multipotent stem cells within different "niches," including the bone marrow, dental pulp, and adipose tissue $(1,6,18,28)$. Moreover, resident stem cells with various grading of potentiality can be virtually

Received May 30, 2011; final acceptance July 31, 2011. Online prepub date: September 22, 2011

Address correspondence to Prof. Carlo Ventura, Laboratory of Molecular Biology and Stem Cell Engineering, National Institute of Biostructures and Biosystems, Strada Maggiore 42, 40125 Bologna, Italy. Tel. \& Fax: +39-051-340339. E-mail: carlo.ventura@unibo.it 
found in any adult organ $(7,10,15)$. Whether stem cell fate may be controlled by the Wi-Fi RF energy remains to be established.

To address this issue, we exposed mouse ES cells to $\mathrm{RF}$ in the field of very low power microwaves through a radio electric asymmetric conveyer (REAC) $(19,20)$, an innovative medical device that was originally designed to use the effects produced by the interaction between the electromagnetic field of the human body (27) and that produced by the instrument. We investigated whether REAC stimulation at Wi-Fi transmission frequency of $2.4 \mathrm{GHz}$ may affect the expression of genes involved in pluripotency or multiple lineage commitment, and may eventually prime the attainment of terminal differentiation features.

\section{MATERIALS AND METHODS}

Description of Radio Electric Asymmetric Conveyer (REAC)

The REAC apparatus was placed into a $\mathrm{CO}_{2}$ incubator, set at a Wi-Fi transmission frequency of $2.4 \mathrm{GHz}$ and its conveyer electrodes were immersed into the culture medium of mouse R1 ES cells.

The distance between the emitter at $2.4 \mathrm{GHz}$ and the culture medium is approximately $35 \mathrm{~cm}$. The electromagnetic quantities have been measured with the spectrum analyzer Tektronix model 2754p, orienting the receiving antenna for maximum signal. With duration of single radiofrequency burst $200 \mathrm{~ms}$ and an off interval of $2.5 \mathrm{~s}$, we have obtained the following results. Radiated power is about $2 \mathrm{~mW}$, electric field $\mathrm{E}=0.4 \mathrm{~V} / \mathrm{m}$, magnetic field $1 \mathrm{~mA} / \mathrm{m}$, specific absorption rate (SAR) $0.128 \mu \mathrm{W} / \mathrm{g}$; determinate $\sigma=1 \mathrm{~A} / \mathrm{V} . \mathrm{m}$ and $\rho=1000 \mathrm{~K}$ $\mathrm{g} / \mathrm{m}^{3}$ the density of radio electric current flowing in the culture medium during the REAC single radiofrequency burst is $J=30 \mu \mathrm{A} / \mathrm{cm}^{2}$. The electromagnetic field around the device is, of course, very irregular because of the presence of the metal walls of the incubator. However, easily detectable points of the highest level could be determined within the incubator. At a distance of $35 \mathrm{~cm}$ from the emitter, and in a very limited area around the receiving antenna we measured values of specific power around $400 \mu \mathrm{W} / \mathrm{m}^{2}$. The instrument that we used is registered under the trademark "Convogliatore di Radianza Modulante-CRM," produced by ASMED, Italy.

\section{ES Cells}

Mouse R1 ES cells were kindly provided by Dr. W. L. Stanford (University of Toronto, Canada). The R1 cells were maintained in the undifferentiated state by culturing onto a layer of mitotically inactivated mouse embryo fibroblasts in the presence of knockout DMEM containing $15 \%$ fetal bovine serum, supplemented with a final concentration of $1,000 \mathrm{U} / \mathrm{ml}$ leukemia inhibitory factor (LIF). Cell differentiation was performed as previously described (34). Briefly, cells were plated onto specialty plates (Costar ultra-low attachment clusters), containing culture medium lacking the supplemental LIF. After 2 days of culture, the resulting embryoid bodies (EBs) were plated onto tissue culture dishes.

\section{Gene Expression}

Total RNA was isolated using Trizol reagent according to the manufacturer's instructions (Invitrogen). Total RNA was dissolved in RNAase-free water and, for RTPCR, cDNA was synthesized in a $50-\mu 1$ reaction volume with $1 \mu \mathrm{g}$ of total RNA and Moloney murine leukemia virus (MMLV) reverse transcriptase (RT) according to the manufacturer's instruction (Invitrogen). Quantitative real-time PCR was performed using an iCycler Thermal Cycler (Bio-Rad). Two $\mu$ l cDNA were amplified in $50-\mu 1$ reactions using Platinum Supermix UDG (Invitrogen), $200 \mathrm{nM}$ of each primer, $10 \mathrm{nM}$ fluorescein (BioRad), and SYBR Green. After an initial denaturation step at $94^{\circ} \mathrm{C}$ for $10 \mathrm{~min}$, temperature cycling was initiated. Each cycle consisted of $94^{\circ} \mathrm{C}$ for 15 s, 55$59^{\circ} \mathrm{C}$ for $30 \mathrm{~s}$, and $60^{\circ} \mathrm{C}$ for $30 \mathrm{~s}$, the fluorescence being read at the end of this step. All primers used in this study were from Invitrogen and previously described $(5,8,12,13,17,35,36)$. To evaluate the quality of product of real-time PCR assays, melting curve analysis was performed after each assay. Relative expression was determined using the "delta-CT method" with glyceraldehyde 3-phosphate dehydrogenase (GAPDH) as reference gene (13).

\section{Immunoblotting Analysis}

ES cells were collected in PBS, then pellets were lysed with cell extraction buffer (Invitrogen). Total cell lysates were electrophoresed on $10 \%$ novex tris-glycine polyacrylamide gels (Invitrogen, $\mathrm{CA})$, in 3-( $N$-morpholino) propanesulfonic acid sodium dodecyl sulfate (MOPS SDS) running buffer, using an XCell SureLock ${ }^{\mathrm{TM}}$ mini-cell, according to the instruction provided by the manufacturer. After protein transfer to polyvinylidene difluoride (PVDF) membranes (Invitrogen, CA), membrane saturation and washing, the immunoreaction was carried out for $1 \mathrm{~h}$ at room temperature in the presence of the primary antibody [antisera against GATA binding protein 4 (GATA4), myogenic differentiation 1 (MyoD), $\beta$-3-tubulin, sex determining region Y-box 2 (Sox2), and Nanog] diluted 1:1,000. After additional washing, membranes were incubated with anti-rabbit (Sox2 and Nanog) or anti-mouse (GATA4, MyoD, $\beta$-3-tubulin) horseradish peroxidase (HRP) conjugated secondary antibody (AbCAM). Targeted protein expression was assessed by a chemioluminescence detection system 
(ECL Western blotting detection reagents were from Amersham Biosciences).

\section{Immunostaining}

R1 cells cultured for 3 days with or without REAC exposure were treated with trypsin, and the resulting suspension was cultured at low density to permit visualization of individual cells. The cultures were fixed with $4 \%$ paraformaldehyde. Cells were exposed for $1 \mathrm{~h}$ at $37^{\circ} \mathrm{C}$ to mouse monoclonal antibodies against $\alpha$-sarcomeric actinin, $\beta$-3-tubulin, myoD or myogenin, or with rabbit polyclonal antibodies against myosin heavy chain, and stained at $37^{\circ} \mathrm{C}$ for $1 \mathrm{~h}$ with fluorescein-conjugated goat IgG. All microscopy was performed with a Leica confocal microscope (LEICA TCSSP5). DNA was visualized with propidium iodide $(1 \mu \mathrm{g} / \mathrm{ml})$.

\section{Data Analysis}

The statistical analysis of the data was performed by using Student's $t$-test, assuming a value of $p<0.05$ as the limit of significance.

\section{RESULTS AND DISCUSSION}

To expose mouse R1 ES cells to Wi-Fi RF energy, we used a REAC apparatus that was originally designed to use the effects produced by the interaction between the electromagnetic field of the human body (27) and that produced by the instrument working with typical range frequencies of $2.4,5.7$, or $10.5 \mathrm{GHz}$, selectable by operator. REAC stimulation has previously been shown to be efficacious in ameliorating stress-related depression and anxiety $(3,14,21-23)$.

Here, a REAC apparatus (Fig. 1), working in a $\mathrm{CO}_{2}$ incubator, was set at a Wi-Fi transmission frequency of $2.4 \mathrm{GHz}$ and its conveyer electrodes were immersed into the culture medium of mouse R1 ES cells (Fig. 2). Radiated power is about $2 \mathrm{~mW}$. Electromagnetic field $\mathrm{E}=$ $0.4 \mathrm{~V} / \mathrm{m}$, with culture medium of mouse R1 ES cells 35 $\mathrm{cm}$ from source. Duration of single radiofrequency burst was $200 \mathrm{~ms}$ with an off interval of $2.5 \mathrm{~s}$.

Under these experimental conditions, we investigated the effects of REAC stimulation on the transcription of prodynorphin, GATA4, and Nkx-2.5 for cardiogenesis, myoD for skeletal myogenesis, and neurogenin 1 for neurogenesis. Real-time RT-PCR revealed a significant increase in prodynorphin gene expression after $24 \mathrm{~h}$ of exposure to REAC, being still evident after 2 days of treatment (Fig. 3A). Interestingly, upon cessation of a 48-h REAC stimulation, the transcriptional enhancement even persisted for the following 7 days (Fig. 3A), being superimposable to that obtained with a continuous 10day exposure (not shown). The REAC effect on prodynorphin transcription is worthy of consideration due to the ability of this gene and its related product dynorphin

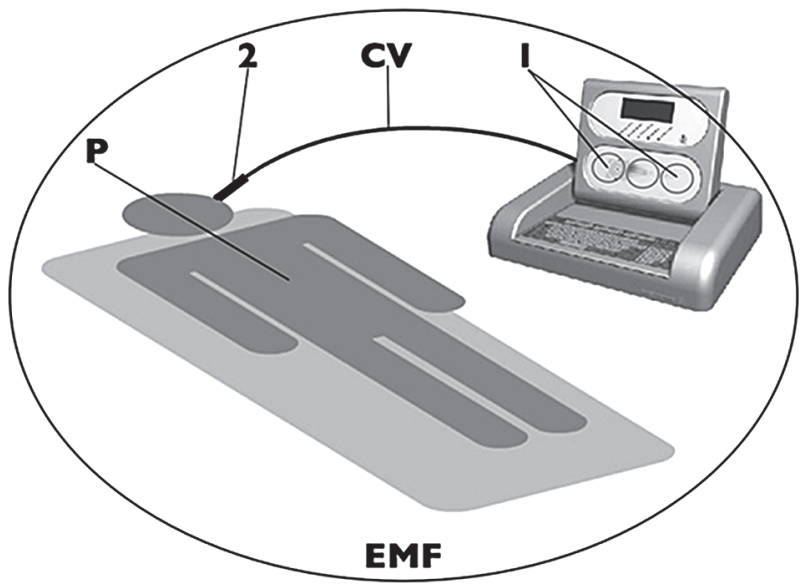

Figure 1. Scheme of the radio electric asymmetric conveyer apparatus (REAC), comprising one or more radiofrequency generators and one or more irradiating antennas (1) which are able to create a radiofrequency field (EMF); one or more electrodes (2) connected through a cable (CV). The radio frequency field (EMF) induces radiofrequency currents in the body, conveyed by the electrodes (2).

B to control cytosolic $\mathrm{Ca}^{2+}$ homeostasis and contractility in adult cardiomyocytes $(29,30,33)$, and induce the transcription of cardiogenic genes in ES cells through the activation of autocrine circuits, $(31,34)$, and "intracrine" signaling by nuclear opioid receptors (35). Highlighting the pivotal role of the prodynorphin gene in cardiogenesis, REAC-treated ES cells showed a significant increase in GATA4 and Nkx-2.5 gene expression (Fig. 3B, C). These genes encode respectively for a zinc finger and a homeodomain essential for cardiogenesis in different animal species $(2,11)$, including humans (24). Transcription of myoD and neurogenin 1 was also significantly enhanced by REAC with similar time courses and persistence after stimulus withdrawal (Fig. 3D, E).

To balance self-renewal and differentiation, ES cells must carefully control the transcription of several factors, including Sox2, Nanog, and octamer binding protein 4 (Oct4) (25). Sox2 can act synergistically with Oct3/4 to activate Oct-Sox enhancers, which regulate the expression of pluripotent stem cell specific genes, including Nanog, Oct $3 / 4$, and Sox 2 itself (9). Ablation of the Oct4 gene in mouse embryos prevented proliferation of inner cell mass (ICM) cells and promoted differentiation into trophectoderm (16). Once expressed, Nanog blocks differentiation (16). Thus, negative regulation of Nanog is required to sustain differentiation during ES cell commitment (4). Early phases of ES cell differentiation, after removal of LIF, involved downregulation of Sox2 expression (Fig. 4A). Here, we show that REAC treatment could further down-regulate Sox2 mRNA levels $24 \mathrm{~h}$ after LIF removal (Fig. 4A). Similar 


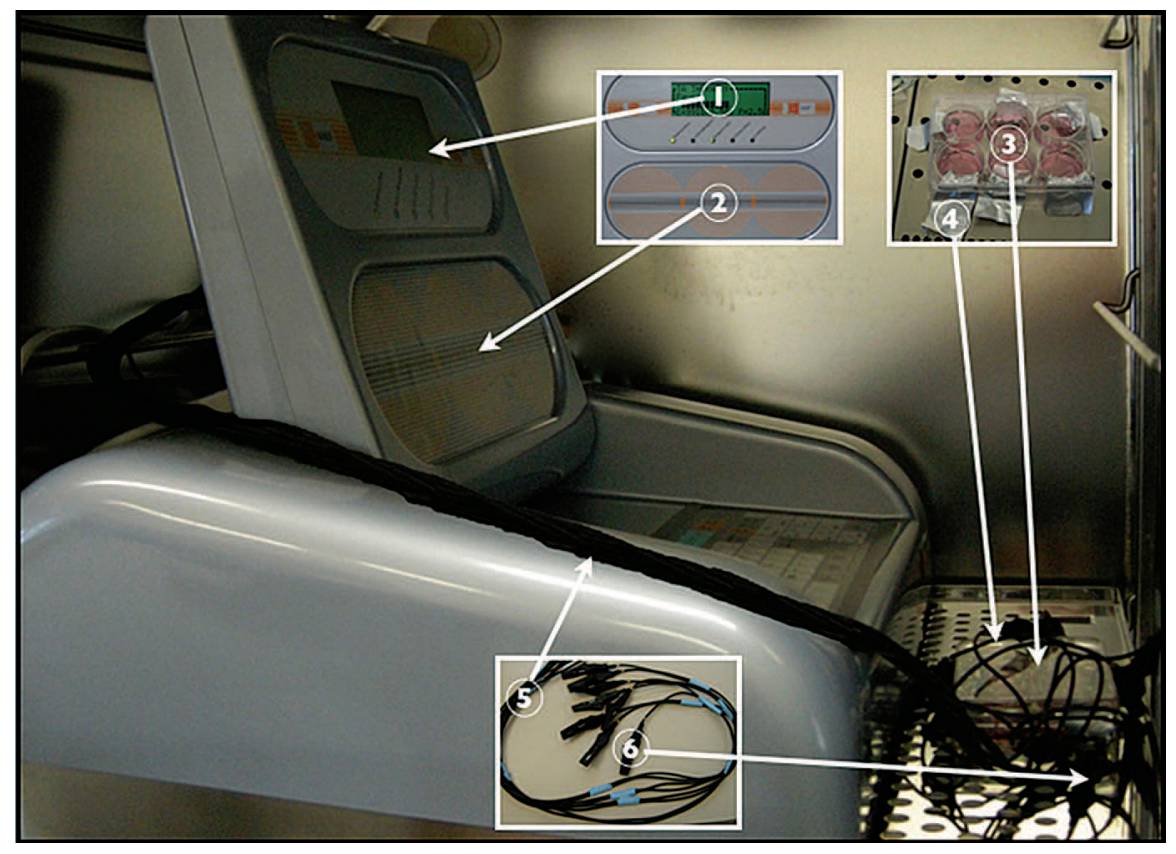

Figure 2. The REAC apparatus adapted to an embryonic stem (ES) cell culture system within a $\mathrm{CO}_{2}$ incubator. 1: Display; 2: Emitter; 3: Tissue culture dishes containing medium with ES cells; 4: Laminar Probes; 5: Cables; 6: Probes.

results, albeit with a different time-course, were yielded by REAC exposure on Oct 4 and Nanog gene expression (Fig. 4B, C).

In order to evaluate whether the observed transcriptional responses may represent a prelude for an increase in the yield of differentiation, we studied the effect of REAC on the expression of a number of tissue-restricted marker proteins. Western blot analysis revealed that GATA4, $\beta$-3-tubulin, and myoD, representative for cardiac, neuronal, and skeletal muscular specification, respectively, were all significantly more expressed in REAC-treated than in untreated cells (Fig. 5A-C). Akin to the transcriptional effect, such an increase was evident after 2 days of treatment, persisting during the following 7 days even in the absence of stimulation (Fig. 5A-C). In REAC-exposed cells, the protein expression of Sox2 and Nanog mirrored the transcriptional responses elicited by REAC stimulation, being significantly down-regulated in exposed, as compared to unexposed cells (Fig. 5D, E).

Overexpression of selected tissue-restricted marker proteins in REAC-exposed cultures was also confirmed by confocal microscopy analysis, (Fig. 6), indicating the ability of REAC treatment to control the patterning of lineage-restricted proteins at the intact cell level. The attainment of a cardiac phenotype was further inferred from the observation that REAC treatment resulted in a remarkable increase in the number of ES-derived spontaneously beating colonies (Fig. 6).

The present data provide evidence that the orchestration of a differentiating program is feasible following ES cell exposure to RF energy within the Wi-Fi emission band, when the RF loop of the REAC apparatus is closed by means of the probes being connected and immersed into the culture medium. Differently from extremely low frequency magnetic fields that only enhanced ES cell cardiogenesis (32), the REAC treatment afforded a consistent increase in the commitment along three major target lineages for regenerative medicine (i.e., cardio-, neuro-, and skeletal myogenesis). Notably these differentiating outcomes could be achieved without the use of chemical agonists or vector-mediated gene delivery. Our findings also raise the largest question as to whether Wi-Fi radiofrequency REAC loop may act as a suitable "physical milieu" that may be supplied to a culture system to optimize stem cell expression of pluripotentiality.

Studies are in progress to unravel the intimate molecular mechanism(s) underlying the REAC action. Addressing whether REAC stimulation may also affect human stem cells will be relevant in view of novel cell therapy approaches. This is the subject of our future investigations on the effects of REAC exposure on the differentiating and rescuing potential of adipose-derived 

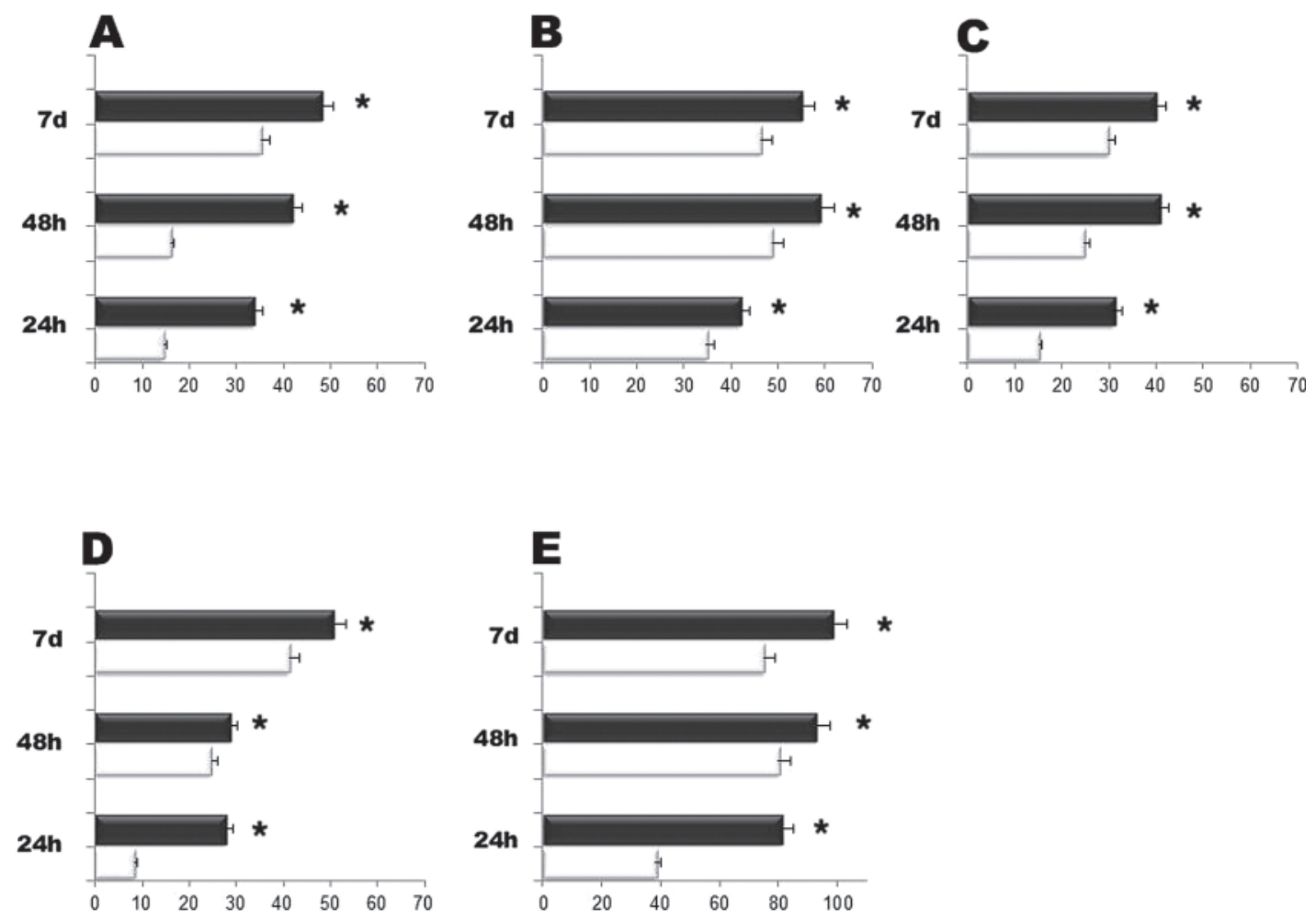

Figure 3. Effect of REAC stimulation on the expression of genes orchestrating ES cell commitment towards cardiogenic, skeletal myogenic, and neurogenic lineages. Cells were exposed for 24 or $48 \mathrm{~h}$ (embryoid bodies; EBs), in the absence (white bars) or presence (black bars) of REAC, or cultured for additional 7 days after $48 \mathrm{~h}$ of EBs aggregation in the absence (white bars) or presence (black bars) of REAC. The amount of prodynorphin (A), GATA binding protein 4 (GATA4) (B), Nkx-2.5 (C), myogenic differentiation 1 (MyoD) (D), and neurogenin 1 (E) mRNA from untreated (white bars) or REAC-treated (black bars) cells was normalized to glyceraldehyde 3-phosphate dehydrogenase (GAPDH) and was plotted as fold change relative to the mRNA expression at the time of leukemia inhibitory factor (LIF) removal (time 0 ), defined as 1 (mean $\pm \mathrm{SE} ; n=6$ ). *Significantly different from untreated cells.
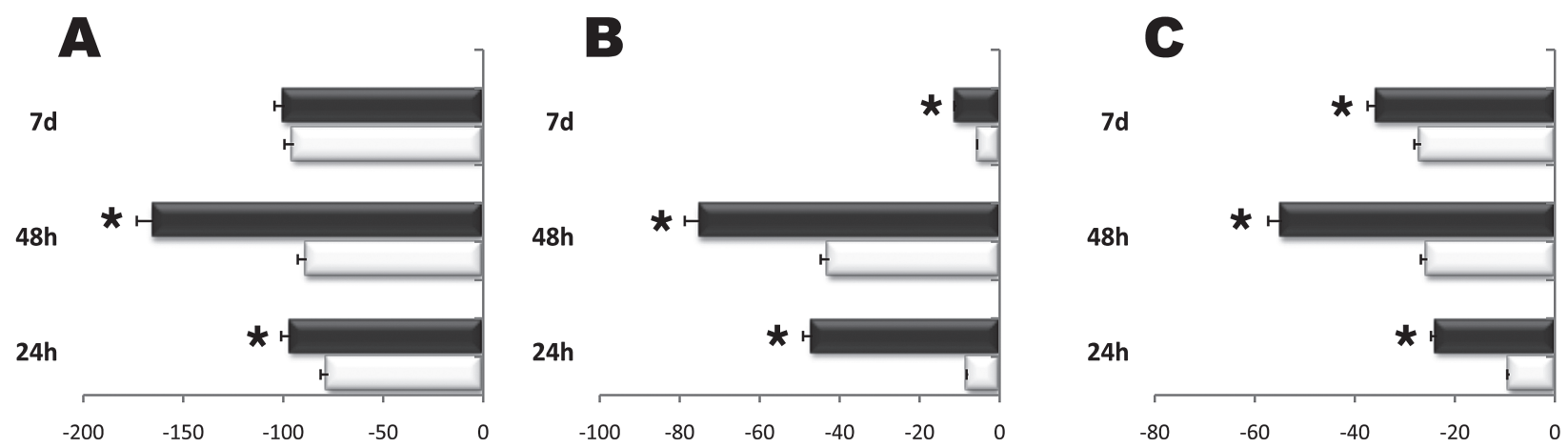

Figure 4. REAC stimulation downregulates the expression of undifferentiated ES cell marker genes. Cells were exposed for 24 or $48 \mathrm{~h}$ (EBs), in the absence (white bars) or presence (black bars) of REAC, or cultured for additional 7 days after $48 \mathrm{~h}$ of EBs aggregation in the absence (white bars) or presence (black bars) of REAC. The amount of sex determining region Y-box 2 (Sox2) (A), octamer binding protein 4 (Oct4) (B), and Nanog (C) mRNA from untreated (white bars) or REAC-treated (black bars) cells was normalized to GAPDH and was plotted as fold change relative to the mRNA expression at the time of LIF removal (time 0), defined as 1 (mean $\pm \mathrm{SE} ; n=6$ ). *Significantly different from untreated cells. 

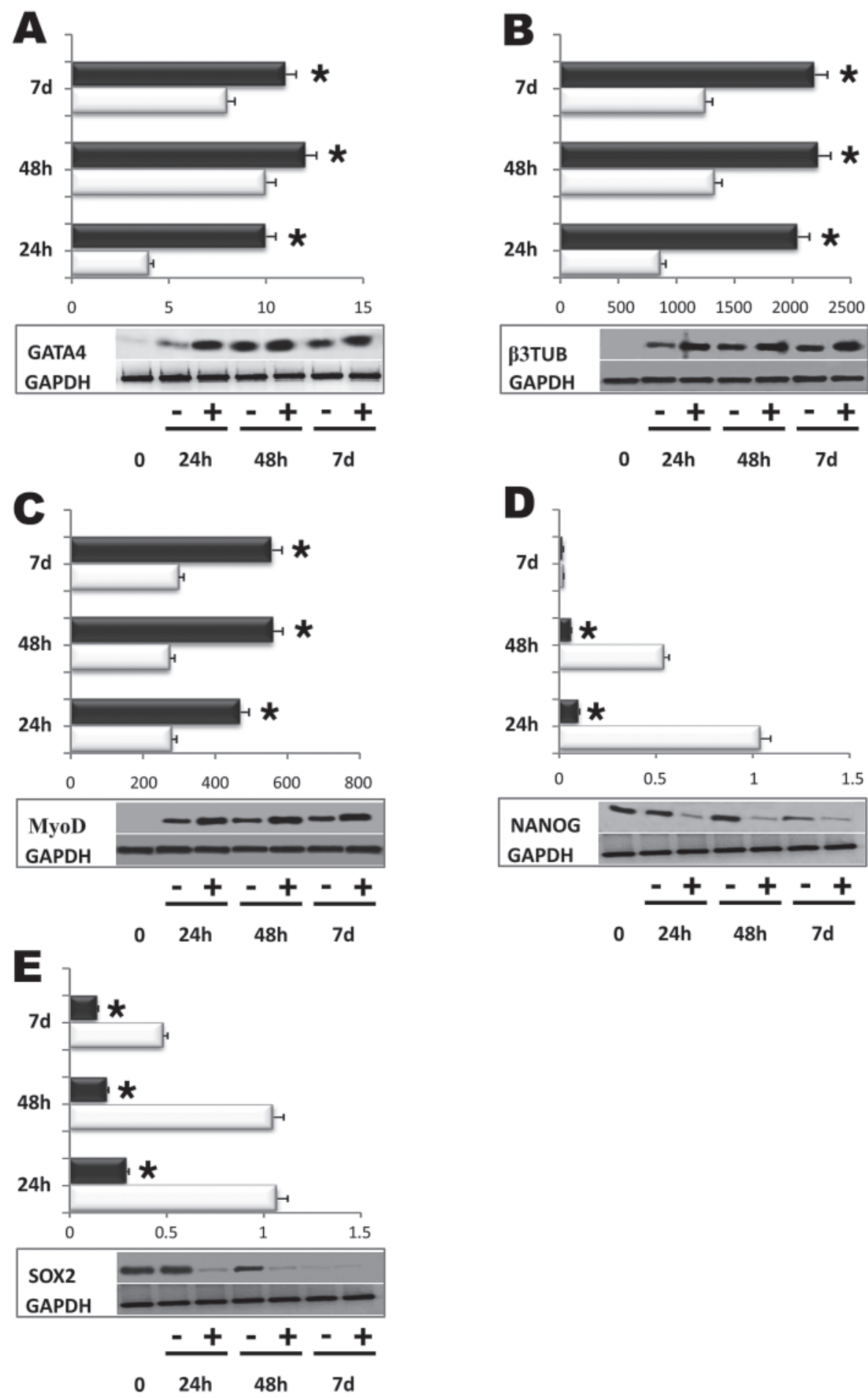

Figure 5. ES cell exposure to REAC modulates the expression of selected, tissue-restricted, and stemness-related proteins. Total lysates were obtained from undifferentiated R1 cells at the time of LIF removal (time 0), or from EBs (24 h, $48 \mathrm{~h}$ ), cultured in the absence (white bars) or presence (black bars) of REAC, or ES cells cultured for additional 7 days after a 48-h aggregation as EBs with (black bars) or without (white bars) REAC stimulation. Samples were subjected to Western blot analysis, using polyclonal antisera raised against GATA4, (A) $\beta$-3-tubulin (B), MyoD (C), Sox2 (D), and Nanog (E). Sizes of the bands were determined with prestained marker proteins. Densitometric analysis was performed using quantity one (BioRad). Data are reported relative to the expression in undifferentiated cells, and normalized to the expression level of GAPDH (mean \pm SE; $n=6$ ). *Significantly different from untreated cells. 


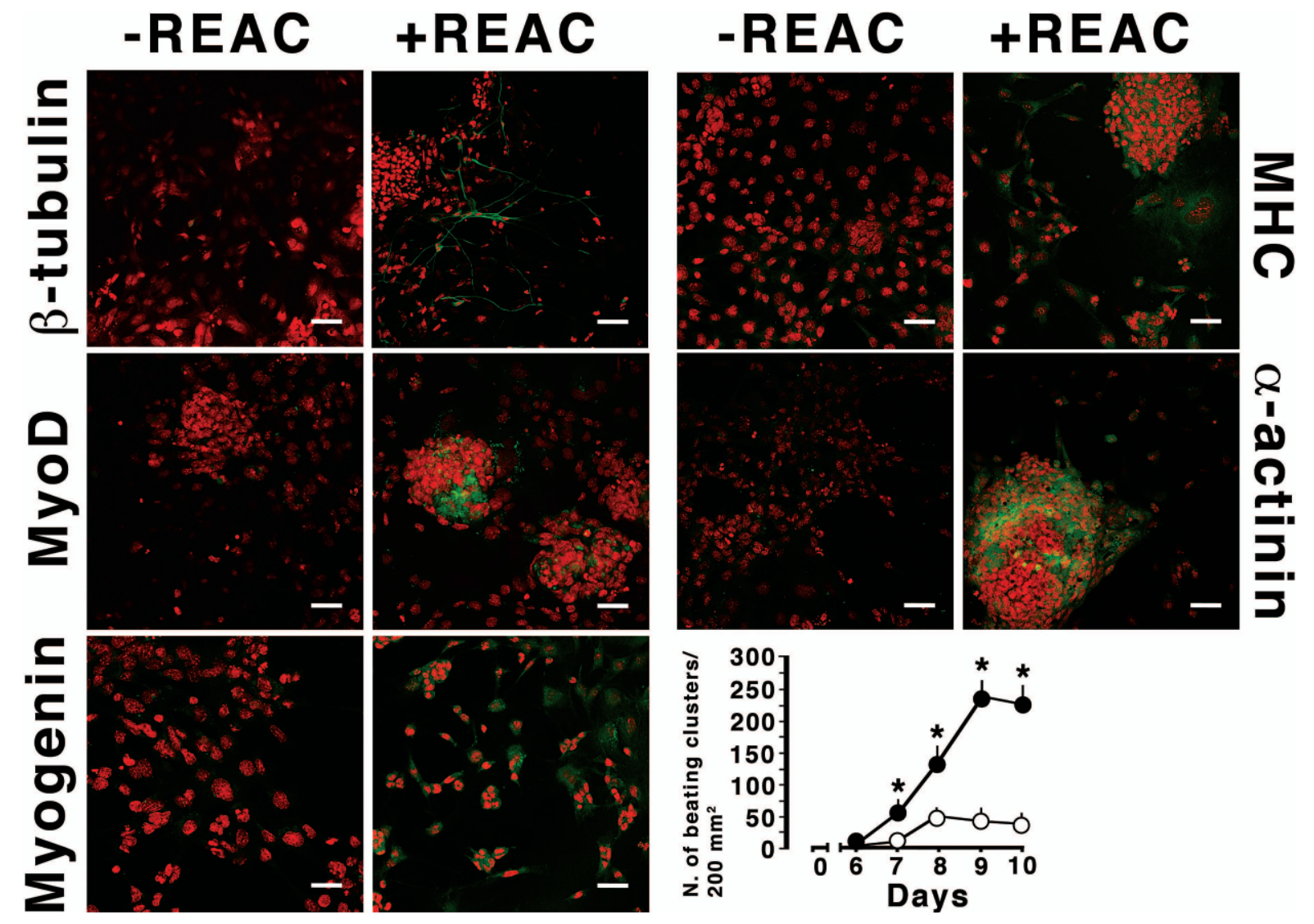

Figure 6. REAC-mediated ES cell differentiation. Expression of $\beta$-3-tubulin ( $\beta$-tubulin), MyoD, myogenin, myosin heavy chain (MHC), and $\alpha$-sarcomeric actinin ( $\alpha$-actinin) was assessed in cells aggregated for $48 \mathrm{~h}$ as EBs in the absence or presence of REAC, and cultured for additional $24 \mathrm{~h}$ in tissue chamber slides suitable for imunofluorescence staining. Scale bars: $40 \mu \mathrm{m}$. Nuclei are labeled with propidium iodide (red). Representative of five separate experiments. The lower right panel reports the analysis of the yield of spontaneously beating colonies obtained from cells aggregated as EBs for $48 \mathrm{~h}$ after LIF removal in the absence (open circles) or presence of REAC (filled circles), and then assayed for the indicated time periods for the appearance of a contractile activity (mean $\pm \mathrm{SE} ; n=6$ ). *Significantly different from untreated cells.

human stem cells, a multipluripotent cell population that can be obtained after minimally invasive harvesting, even in the absence of any enzymatic digestion or growth factor additives (26).

ACKNOWLEDGMENTS: We thank Dr. Pierluigi Pompili, Electric Engineer, Dr. Gianfranco Moschini, Electric Engineer, and Dr. Stelvio Castelfiori, Doctor of Physics, for their essential help in the electronic and physical measurements. Lucia Aravagli, M.D., and Stefania Bini, M.D. of Rinaldi Fontani Institute, Florence, Italy for their helpful support. This research was supported by Regione Emilia Romagna, Programma di Ricerca Regione-Università 2007/2009, Area $1 b$ "Medicina rigenerativa," Italy; Ministero della Salute, Italy, Programma per la Ricerca Sanitaria: attività di Ricerca sulle Cellule Staminali; Fondazione Fornasini, Poggio Renatico, Italy; Fondazione Cardinale Giacomo Lercaro, Bologna, Italy; Fondazione Luisa Fanti-Melloni, Bologna, Italy; Tavola Valdese, Rome, Italy. The authors declare no conflicts of interest.

\section{References}

1. Baglioni, S.; Francalanci, M.; Squecco, R.; Lombardi, A.; Cantini, G.; Angeli, R.; Gelmini, S.; Guasti, D.; Benvenuti, S.; Annunziato, F.; Bani, D.; Liotta, F.; Francini, F.; Perigli, G.; Serio, M.; Luconi, M. Characterization of human adult stem-cell populations isolated from visceral and subcutaneous adipose tissue. FASEB J. 23(10):3494-3505; 2009.

2. Biben, C.; Harvey, R. P. Homeodomain factor Nkx2-5 controls left/right asymmetric expression of bHLH gene eHand during murine heart development. Genes Dev. 11(11):1357-1369; 1997.

3. Castagna, A.; Rinaldi, S.; Fontani, V.; Aravagli, L.; Mannu, P.; Margotti, M. L. Does osteoarthritis of the knee also have a psychogenic component? Psycho-emotional treatment with a radio-electric device vs. intra-articular injection of sodium hyaluronate: An open-label, naturalistic study. Acupunct. Electrother. Res. 35(1-2):1-16; 2010.

4. Chambers, I.; Colby, D.; Robertson, M.; Nichols, J.; Lee, S.; Tweedie, S.; Smith, A. Functional expression cloning 
of Nanog, a pluripotency sustaining factor in embryonic stem cells. Cell 113(5):643-655; 2003.

5. Chew, J. L.; Loh, Y. H.; Zhang, W.; Chen, X.; Tam, W. L.; Yeap, L. S.; Li, P.; Ang, Y. S.; Lim, B.; Robson, P.; Ng, H. H. Reciprocal transcriptional regulation of Pou5f1 and Sox 2 via the Oct4/Sox 2 complex in embryonic stem cells. Mol. Cell. Biol. 25(14):6031-6046; 2005.

6. Daley, G. Q.; Scadden, D. T. Prospects for stem cellbased therapy. Cell 132(4):544-548; 2008.

7. Ding, D. C.; Shyu, W. C.; Lin, S. Z. Mesenchymal stem cells. Cell Transplant. 20(1):5-14; 2011

8. Dobbin, E.; Graham, C.; Corrigan, P. M.; Thomas, K. G.; Freeburn, R. W.; Wheadon, H. Tel/PDGFRbeta induces stem cell differentiation via the Ras/ERK and STAT5 signaling pathways. Exp. Hematol. 37(1):111-121; 2009.

9. Kashyap, V.; Rezende, N. C.; Scotland, K. B.; Shaffer, S. M.; Persson, J. L.; Gudas, L. J.; Mongan, N. P. Regulation of stem cell pluripotency and differentiation involves a mutual regulatory circuit of the NANOG, OCT4, and SOX2 pluripotency transcription factors with polycomb repressive complexes and stem cell microRNAs. Stem Cells Dev. 18(7):1093-1108; 2009.

10. Lin, S. Z. Advances in translational stem cell research and therapies. Cell Transplant. 20(1):1-3; 2011.

11. Lints, T. J.; Parsons, L. M.; Hartley, L.; Lyons, I.; Harvey, R. P. Nkx-2.5: A novel murine homeobox gene expressed in early heart progenitor cells and their myogenic descendants. Development 119(3):969; 1993.

12. Maioli, M.; Asara, Y.; Pintus, A.; Ninniri, S.; Bettuzzi, S.; Scaltriti, M.; Galimi, F.; Ventura, C. Creating prodynorphin-expressing stem cells alerted for a high-throughput of cardiogenic commitment. Regen. Med. 2(2):193-202; 2007.

13. Maioli, M.; Santaniello, S.; Montella, A.; Bandiera, P.; Cantoni, S.; Cavallini, C.; Bianchi, F.; Lionetti, V.; Rizzolio, F.; Marchesi, I.; Bagella, L.; Ventura, C. Hyaluronan esters drive Smad gene expression and signaling enhancing cardiogenesis in mouse embryonic and human mesenchymal stem cells. PLoS One 5(11):e15151; 2010.

14. Mannu, P.; Rinaldi, S.; Fontani, V.; Castagna, A.; Margotti, M. L. Radio electric treatment vs. Es-Citalopram in the treatment of panic disorders associated with major depression: An open-label, naturalistic study. Acupunct. Electrother. Res. 34(3-4):135-149; 2009.

15. Mimeault, M.; Batra, S. K. Recent progress on tissue-resident adult stem cell biology and their therapeutic implications. Stem Cell Rev. 4(1):27-49; 2008.

16. Nichols, J.; Zevnik, B.; Anastassiadis, K.; Niwa, H.; Klewe-Nebenius, D.; Chambers, I.; Schöler, H.; Smith, A Formation of pluripotent stem cells in the mammalian embryo depends on the POU transcription factor Oct4. Cell 95(3):379-391; 1998.

17. Rawls, A.; Morris, J. H.; Rudnicki, M.; Braun, T.; Arnold, H. H.; Klein, W. H.; Olson, E. N. Myogenin's functions do not overlap with those of MyoD or Myf-5 during mouse embryogenesis. Dev. Biol. 172(1):37-50; 1995.

18. Riazi, A. M.; Kwon, S. Y.; Stanford, W. L. Stem cell sources for regenerative medicine. Methods Mol. Biol. 482:55-90; 2009.

19. Rinaldi, S.; Fontani, V. Radioelectric asimmetric conveyer for therapeutic use. Patent N. EP1301241. April 16, 2003.

20. Rinaldi, S.; Fontani, V. Radioelectric asimmetric conveyer for therapeutic Use. Patent N. US 7333859. February 19, 2008.
21. Rinaldi, S.; Fontani, V.; Aravagli, L.; Mannu, P. Psychometric evaluation of a radio electric auricular treatment for stress related disorders: A double-blinded, placebocontrolled controlled pilot study. Health Qual. Life Outcomes 8:31; 2010.

22. Rinaldi, S.; Fontani, V.; Aravagli, L.; Margotti, M. L. Psychological and symptomatic stress-related disorders with radio-electric treatment: Psychometric evaluation. Stress Health 26(5):350-358; 2010.

23. Rinaldi, S.; Fontani, V.; Moretti, E.; Rosettani, B.; Aravagli, L.; Saragò, G.; Collodel, G. A new approach on stress-related depression \& anxiety: Neuro-psycho-physical-optimization with radio electric asymmetric-conveyer. Indian. J. Med. Res. 132:189-194; 2010.

24. Schott, J. J.; Benson, D. W.; Basson, C. T.; Pease, W.; Silberbach, G. M.; Moak, J. P.; Maron, B. J.; Seidman, C. E.; Seidman, J. G. Congenital heart disease caused by mutations in the transcription factor NKX2-5. Science 281(5373):108-111; 1998.

25. Sun, Y.; Li, H.; Yang, H.; Rao, M. S.; Zhan, M. Mechanisms controlling embryonic stem cell self-renewal and differentiation. Crit. Rev. Eukaryot. Gene Expr. 16(3): 211-231; 2006.

26. Tremolada, C.; Palmieri, G.; Ricordi, C. Adipocyte transplantation and stem cells: Plastic surgery meets regenerative medicine. Cell Transplant. 19(10):1217-1223; 2010.

27. Valberg, P. A.; van Deventer, T. E.; Repacholi, M. H. Workgroup report: Base stations and wireless networksradiofrequency $(\mathrm{RF})$ exposures and health consequences. Environ. Health Perspect. 115(3):416-424; 2007.

28. Ventura, C.; Cantoni, S.; Bianchi, F.; Lionetti, V.; Cavallini, C.; Scarlata, I.; Foroni, L.; Maioli, M.; Bonsi, L.; Alviano, F.; Fossati, V.; Bagnara, G. P.; Pasquinelli, G.; Recchia, F. A.; Perbellini, A. Hyaluronan mixed esters of butyric and retinoic acid drive cardiac and endothelial fate in term placenta human mesenchymal stem cells and enhance cardiac repair in infarcted rat hearts. J. Biol. Chem. 282(19): 14243-14252; 2007.

29. Ventura, C.; Capogrossi, M. C.; Spurgeon, H. A.; Lakatta, E. G. Kappa-opioid peptide receptor stimulation increases cytosolic $\mathrm{pH}$ and myofilament responsiveness to $\mathrm{Ca}^{2+}$ in cardiac myocytes. Am. J. Physiol. 261(5 Pt 2):H1671H1674; 1991.

30. Ventura, C.; Guarnieri, C.; Stefanelli, C.; Cirielli, C.; Lakatta, E. G.; Capogrossi, M. C. Comparison between alpha-adrenergic- and K-opioidergic-mediated inositol (1, $4,5) \mathrm{P}$ /inositol $(1,3,4,5) \mathrm{P} 4$ formation in adult cultured rat ventricular cardiomyocytes. Biochem. Biophys. Res. Commun. 179(2):972-978; 1991.

31. Ventura, C.; Maioli, M. Opioid peptide gene expression primes cardiogenesis in embryonal pluripotent stem cells. Circ. Res. 87(3):189-194; 2000.

32. Ventura, C.; Maioli, M.; Asara, Y.; Santoni, D.; Mesirca, P.; Remondini, D.; Bersani, F. Turning on stem cell cardiogenesis with extremely low frequency magnetic fields. FASEB J. 19(1):155-157; 2005.

33. Ventura, C.; Spurgeon, H.; Lakatta, E. G.; Guarnieri, C.; Capogrossi, M. C. Kappa and delta opioid receptor stimulation affects cardiac myocyte function and $\mathrm{Ca}^{2+}$ release from an intracellular pool in myocytes and neurons. Circ. Res. 70(1):66-81; 1992.

34. Ventura, C.; Zinellu, E.; Maninchedda, E.; Fadda, M.; Maioli, M. Protein kinase C signaling transduces 
endorphin-primed cardiogenesis in GTR1 embryonic stem cells. Circ. Res. 92(6):617-622; 2003.

35. Ventura, C.; Zinellu, E.; Maninchedda, E.; Maioli, M. Dynorphin B is an agonist of nuclear opioid receptors coupling nuclear protein kinase $\mathrm{C}$ activation to the transcription of cardiogenic genes in GTR1 embryonic stem cells. Circ. Res. 92(6):623-629; 2003.
36. Wu, M.; Zhang, Y.; Wu, N.; Shen, Y. Histone marks and chromatin remodelers on the regulation of neurogenin 1 gene in RA induced neuronal differentiation of P19 cells. J. Cell. Biochem. 107(2): 264-271; 2009. 